\title{
PRELIMINARES DE UNA HISTORIA: HACIA UNA CARACTERIZACIÓN ESPECÍFICA DE LA FANTASÍA ÉPICA
}

\author{
A PRELIMINARY APPROACH TO A HISTORY: \\ TOWARDS A SPECIFIC CHARACTERIZATION OF HIGH FANTASY \\ Mariano MARTÍN RODRÍGUEZ \\ Investigador independiente \\ martioa@yahoo.com
}

\begin{abstract}
Resumen: La historiografía de la fantasía épica adolece de la vaguedad de la teoría sobre esta modalidad ficcional, ya que no se la suele distinguir de otros tipos de ficción con elementos sobrenaturales. Siguiendo las teorías de Tolkien, Waggoner y Trębicki, este ensayo constituye un intento de definir y caracterizar la fantasía épica, distinguiéndola mediante rasgos estructurales y retóricos de otros tipos afines de fantasía en la ficción, para poder saber específicamente de qué se está hablando al acometer una historia comparada de la fantasía épica.
\end{abstract}

Palabras clave: Fantasía épica. Caracterización. Mundos secundarios. Historia de la fantasía épica.

Abstract: The historiography of high fantasy suffers from the theoretical vagueness about this kind of fiction, since it is not usually distinguished from other kinds of fiction with supernatural elements. Following the theories of Tolkien, Waggoner and Trębicki, this essay constitutes an attempt to define and describe high fantasy, distinguishing it through structural and rhetorical features from other related fantasy fiction genres in order to establish what we are specifically talking about when we undertake a comparative history of high fantasy.

Keywords: High fantasy. Description. Secondary worlds. History of high fantasy.

En los últimos años se ha producido en España una amplia apertura de los estudios filológicos a modalidades literarias como la ficción ${ }^{1}$ fantástica y la científica que, durante la segunda mitad del siglo pasado, apenas habían recibido atención académica, además

\footnotetext{
${ }^{1}$ En el presente ensayo nos referiremos únicamente a la ficción literaria, incluida la dramática. En cuanto a la ficción en general, seguimos la definición de Frank Zipfel: "fiktive Geschichten sind Geschichten von nicht-wirklichen Ereignisträgern, die an nicht-wirklichen Orten zu nicht-wirklichen Zeiten spielen" (2001: 79).
} 
de haber solido estar privadas de prestigio cultural y consideración crítica fuera de los círculos de sus aficionados. En cambio, la bibliografía sobre estas modalidades de ficción se ha multiplicado este siglo hasta ser ya centenares los estudios académicos sobre sus distintos aspectos (teóricos, históricos, etc.). Muy buenos ejemplos de ello pueden ser dos grandes sumas sin apenas equivalentes en otros países, la Historia de lo fantástico en la cultura española contemporánea (1900-2015) (Roas, 2017) e Historia de la ciencia ficción en la cultura española (López-Pellisa, 2018). En cambio, no existe ni siquiera el proyecto de confeccionar un libro similar sobre la fantasía épica española. Aunque siempre es aventurado conjeturar las causas de este fenómeno de omisión académica, y no solo en España, de una clase de ficción cuya presencia en la cultura actual es patente (recuérdese la vigencia de la obra de J. R. R. Tolkien o fenómenos televisivos como la serie A Game of Thrones [Juego de tronos] $\left.{ }^{2}, 2011-2019\right)$, podríamos pensar que un motivo podría ser la vaguedad del propio concepto de fantasy. No parece estar clara su delimitación con respecto a otros tipos de ficción y, en consecuencia, los límites de su objeto, que es la condición previa para su estudio histórico.

Ya hace unas décadas, Neil Cornwell señaló el problema al declarar que "a certain inconsistency, not to say confusion, exists in the application of the expressions 'the fantastic', 'fantastic' (as an adjective) and 'fantasy"' (1990: 27). Limitándonos a este último concepto, consultar para entenderlo mejor The Encyclopedia of Fantasy (Clute, 1998) y libros dedicados aparentemente a la teoría de la fantasy como fenómeno literario específico y distinto a the fantastic, tales como el pionero de Irwin (1976) y el muy citado de Mendlesohn (2008), expone a una decepción. Su división de la fantasy en diversas modalidades sigue, en cualquier caso, unos criterios más bien intuitivos que dan lugar a lecturas ciertamente interesantes, pero que no delimitan ni aclaran realmente los conceptos. Leyendo a estos y otros teóricos (por ejemplo, Pesch, 1990), seguramente nos seguiremos quedando en ayunas si queremos saber cuáles son las características específicas de la fantasy, o high fantasy, para ser más exactos, ya que es a esta última a la que nos referimos aquí únicamente. A ese respecto, ¿existen marcas narratológicas y textuales comunes a las grandes creaciones de la fantasía épica (o heroica), que es como solemos traducir high fantasy, que permitan caracterizarla de forma específica y justifiquen en alguna medida su clasificación como especie literaria aparte, tal como se

\footnotetext{
${ }^{2}$ Son nuestras todas las traducciones de los títulos de obras de ficción, salvo aquellas correspondientes a versiones ya publicadas, cuyos datos bibliográficos pueden encontrarse en repertorios y catálogos. Los ejemplos aducidos de cada tipo de fantasía afín a la épica y a menudo confundida con ella proceden todos de la literatura española en lengua castellana (incluidas las versiones de autor de textos propios publicados antes en otras lenguas) y pretenden ilustrar así la riqueza en esa literatura de la ficción que podríamos denominar fabulosa. En el sentido aquí adoptado, la fantasía fabulosa abarca la fantasía épica y todas las ficciones ambientadas en mundos secundarios de cualquier clase, esto es, todo lo que en inglés se denomina fantasy en general. En otras palabras, se trata de lo que los antiguos llamaban la fábula como modalidad literaria opuesta a la historia, que se supone ser real y fiel a los sucesos del mundo primario.
} 
considera en la práctica y el consumo literarios actuales ${ }^{3}$ ? A este respecto, ¿qué tienen en común los mundos ficticios ${ }^{4}$ de esta clase creados, entre otros, por famosos cultivadores anglófonos de la modalidad ${ }^{5}$ como Lord Dunsany (Pegāna), Clark Ashton Smith (Hyperborea), Robert E. Howard (Hyboria), Fritz Leiber (Nehwon), Fletcher Pratt (Dalarna), J. R. R. Tolkien (Middle-earth), L. Sprague de Camp (Novaria), Michael Moorcock (Melniboné), Ursula K. Le Guin (Earthsea), Samuel Delany (Nevèrÿon), Piers Anthony (Xanth), Terry Pratchett (Discworld), George R. R. Martin (Westeros) y Christopher Paolini (Alagaësia)?

Uno de esos escritores acompañó su labor creativa con otra teórica que contribuye a caracterizar sus propios universos ficticios. En su conferencia "On Fairy-stories", pronunciada en 1939 y publicada en 1947, Tolkien se esforzó por distinguir sus propias sub-creations de universos ficticios fabulosos y enchanted de aquellos maravillosos de los cuentos de hadas, entonces prácticamente relegados a lectores infantiles. Para ello, recurrió deliberadamente a otro término, fantasy, en cuya fortuna posterior no hace falta insistir:

For my present purpose I require a word which shall embrace both the Sub-creative Art in itself and a quality of strangeness and wonder in the Expression, derived from the Image: a quality essential to fairy-story. I propose, therefore, $[\ldots]$ to use Fantasy for this purpose: in a sense, that is, which combines with its older and higher use as an equivalent of Imagination the derived notions of "unreality" (that is of unlikeness to the Primary

\footnotetext{
${ }^{3}$ El presente artículo se limita a proponer una caracterización general de una serie de obras literarias cuyos universos ficcionales presentan una serie de rasgos comunes que han permitido históricamente su clasificación en una categoría determinada, sobre todo desde que, según Jamie Williamson (2019), Lin Carter creó la fantasy como especie editorial mediante su colección Ballantine Adult Fantasy Series. Los autores centrales en esta colección y en la fantasy subsiguiente son J. R. R. Tolkien y Robert E. Howard, cuyos ciclos ficcionales de mayor éxito son, como veremos, el resultado de un procedimiento de creación de mundos secundarios de carácter imaginario, autónomo y cerrado que suscitó los suficientes imitadores o emuladores como para propiciar la constitución de un conjunto de ficciones específico y públicamente reconocido.

${ }^{4}$ Sobre la teoría de los mundos posibles y ficticios, véase el claro resumen realizado por Dorian Espezúa Salmón (2006). Aquí seguimos la definición fenomenológica de Mark J. P. Wolf: "The term 'world', as it is being used here, is not simply geographical but experiential; that is, everything that is experienced by the characters involved, the elements enfolding someone's life (culture, nature, philosophical worldviews, places, customs, events, and so forth)" (2012: 25).

${ }_{5}^{5}$ No entraremos en la discusión sobre si la fantasy o fantasía épica es un género o un modo, conceptos ambos que los teóricos literarios mismos han empleado de manera muy diversa según los propósitos perseguidos por cada uno de ellos. Como bien señaló Javier Rodríguez Pequeño, "[l]a cuestión de los géneros literarios es una de las más debatidas a lo largo de la historia, y al mismo tiempo una de las más controvertidas" (2008: 11), y no será aquí donde contribuyamos a tal controversia, por lo que hemos preferido emplear términos más generales como modalidad, clase o tipo. Con todo, indicaremos que, desde nuestro punto de vista, la fantasía épica no es un género literario, sino más bien un modo, o mejor dicho un submodo de ficción. Siguiendo la clásica división estructural de la ficción tradicional y globalmente llamada fantástica, Tzvetan Todorov habla de lo merveilleux como un genre, aunque su empleo de la sustantivación generalizadora del adjetivo parece sugerir que se trata más bien de un modo de ficción, del que menciona como ejemplo el cuento de hadas, ya que "en fait, le conte des fées n'est une des variétés du merveilleux" (1976: 59). La fantasía épica no es, según creemos, más que otra variedad de lo maravilloso todoroviano o, mejor dicho quizás, lo fabuloso, para no confundirlo con el cuento maravilloso o cuento de hadas.
} 
World), of freedom from the domination of observed "fact", in short of the fantastic. I am thus not only aware but glad of the etymological and semantic connections of fantasy with fantastic: with images of things that are not only "not actually present", but which are indeed not found in our primary world at all, or are generally believed not to be found there (2014: 59-60).

Dados el prestigio literario del autor y la propia elocuencia de este pasaje, no es extraño que el propio concepto contemporáneo de fantasy pueda atribuirse en gran medida a este empleo de la palabra por Tolkien, pero nos atrevemos a señalar que no llegó a caracterizar ni a delimitar completamente su objeto. En primer lugar, no sustituyó completamente el término de fairy-story por el propuesto de fantasy, de modo que podría pensarse que lo propio y original de su aportación quedó disimulado por la continuidad del viejo léxico. Por otra parte, al conectar fantasy con fantastic, parece difuminarse toda distinción entre la fantasy, como clase de ficción generada mediante un proceso de $s u b$ creation por el que se crean mundos secundarios irreales e independientes de los hechos observados en nuestro mundo primario, y la ficción fantástica, cuya caracterización ha hecho correr ríos de tinta, pero que se suele distinguir por la intrusión problemática en un universo ficcional basado en el mundo primario de entes o elementos imposibles en el mundo fenoménico. Según la taxonomía de la ficción derivada de la semiología de los mundos posibles propuesta por Andrzej Zgorzelski, la literatura fantástica se caracterizaría como sigue:

Fantastic literature (FL), which, while taking for granted the implied reader's linguistic competence determining his knowledge of phenomenal reality, presupposes the confrontation of its order with a different one, signalling the presupposition by the presentation of both or more orders within the text. It presents all the orders as models, stressing the strangeness of those it confronts with the known order of the empirical reality (Zgorzelski, 1984: 302).

Los mundos secundarios arriba recordados de Tolkien y otros autores no presentan en ningún caso esa confrontación con el mundo primario. Además, la confrontación se produce fundamentalmente por el choque entre una concepción racional del mundo fenoménico que no admite la ruptura de las leyes naturales de nuestro universo y la posible existencia de seres y fenómenos que, por no atenerse a esas leyes, son inexplicables por medios racionales. En cambio, para Tolkien, la fantasy "doesn't destroy or even insult Reason" (2014: 65). Así pues, cabe excluir de la fantasy, todas las ficciones no miméticas que se ajusten a la caracterización taxonómica arriba citada ${ }^{6}$. En cambio, la literatura fantasy sería más bien de tipo exomimético:

Exomimetic literature (EL), which, while taking for granted reader's [sic] linguistic competence determining their knowledge of phenomenal reality, presupposes speculation

\footnotetext{
${ }^{6}$ El respeto de la razón por la fantasy permite excluir de ella también la ficción absurdista, entendiendo por tal aquella que presenta, en un mundo afín al primario, hechos y situaciones incongruentes y racionalmente injustificados en el mundo fenoménico, como en la serie de "cuentos para perros” de Miguel Mihura.
} 
about other possible models of reality either by way of a dreamlike design or by means of rational extrapolation and analogy, presenting these models without any direct textual confrontation between them and the empirical model of the universe (Zgorzelski ${ }^{7}$ apud Trębicki, 2014: 486).

Esta definición abarcaría, pues, la ciencia ficción, que sería la creada "by means of rational extrapolation and analogy", y también la creada "by way of a dreamlike design", que suponemos designa la fantasy en sentido amplio. Ambas se caracterizarían por su independencia ontológica del mundo fenoménico, a diferencia de la ficción mimética aún hegemónica hoy, la cual "pretends that the fictional universe is a copy of the phenomenal one" (485). Pero ¿qué distinguiría ambas clases de ficción especulativa? Ampliando la teoría de Zgorzelski, Grzegorz Trębicki habla, por un lado, de "science fiction" y, por otro, de "secondary-world fantasy". Aunque su propósito es señalar sus similitudes estructurales por encima de su oposición temática entre la ciencia de la primera y la magia de la segunda, la denominación más precisa que elige para sustituir la demasiado general de fantasy sugiere el carácter esencial en ella de ese mundo secundario, que sería un mundo aparte y segundo equivalente, en la esfera de la ficción, al primero o primario, es decir, a aquel fenoménico en que desarrollamos nuestras vidas. La (high) fantasy sería la manifestación y el resultado de:

a strategy aimed at the creation of a secondary world model with its own precisely described spatial and temporal parameters, its own social and ontological order, and its own causality, unusual from the point of view of mimetic reality but perfectly coherent and logical within the fictional universe (2014: 488).

Es el carácter "unusual from the point of view of mimetic reality" lo que la distinguiría de la ciencia ficción, cuya obediencia a la causalidad racional, tal como esta funciona en el marco del método científico, la hace compartir su modo de obtención de la verosimilitud con la ficción mimética, entendida esta como la que pretende ser una copia o reflejo del mundo primario o fenoménico. En consecuencia, ambas modalidades de ficción exomimética presentan lo que Tolkien llamó "the inner consistency of reality" (2014: 59), pero como el mundo secundario de la high fantasy o fantasía épica es específico, no está sujeto a las leyes naturales del mundo fenoménico y admite, en consecuencia, entes y sucesos que, en los mundos de la ficción mimética (y también de la fictocientífica), serían sobrenaturales o, simplemente, anaturales, tales como la magia o la intervención de divinidades. Aunque no sea imprescindible que las leyes de ese mundo secundario sean ajenas a las que rigen el universo fenoménico ${ }^{8}, \operatorname{los}_{\text {mundos épico- }}$

\footnotetext{
${ }^{7}$ En un ensayo anterior suyo, este tipo de literatura se denomina "[n]onmimetic literature" (Zgorzelski, 1984: 302) y en él incluye "the heroic fantasy, dystopia, and science fiction" (303), pero el tenor de la definición es prácticamente el mismo. Preferimos seguir la denominación y definición posteriores citadas y utilizadas por Trębicki.

${ }^{8}$ Los mundos épico-fantásticos coinciden en esto con los de la ficción maravillosa, ya que "los mundos maravillosos pueden conformarse solo con fuerzas naturales y personas con dotes aléticas [sic] naturales y
} 
fantásticos son independientes del nuestro primario y poseen su propio orden social, cultural y ontológico, como ocurre, por ejemplo, en Escuela de mandarines (1974), de Miguel Espinosa, con sus hiperbólicas convenciones de cómputo cronológico. Lo dicho vale tanto si tal mundo secundario está localizado en lugares imaginarios dotados de nombre propio (por ejemplo, la Feliz Gobernación en aquella novela de Espinosa) como si permanece en una vaguedad simbólica (por ejemplo, el reino de la comedia dramática de Eduardo Marquina El pavo real, estrenada con gran éxito en 1922). La misma afirmación vale si el mundo secundario corresponde a una geografía inventada de nuestro planeta (por ejemplo, la ciudad de Jaralad en "Benagissal el profeta", cuento de 1924 firmado por Alfonso Maseras) o de otros (por ejemplo, Leyendas del planeta Thámyris [1982], de Joan Manuel Gisbert). También vale si su espacio coincide con alguno de la Tierra que haya existido realmente, pero al que se le ha despojado de su historicidad, como hizo Rafael Sánchez Ferlosio con la Iberia prerromana en su novela épico-fantástica sin elementos sobrenaturales El testimonio de Yarfoz (1986). De hecho, la acción épicofantástica puede situarse:

En un ámbito por completo imaginario, fabuloso, autónomo respecto del nuestro, con sus leyes propias, su geografía, historia, cosmogonía, organización político-social, lenguaje, población humana o de otras criaturas. [...] Este ámbito puede encontrarse fuera de nuestro planeta Tierra. $O$ también aquí, pero en una época muy remota o indefinida, y/o en un lugar inconcreto o inventado (Robles, 2018: 77).

Esta descripción de los mundos secundarios épico-fantásticos, que se ajusta a la definición propuesta por Trębicki (y Tolkien), coincide asimismo con otra de aire más impresionista, de Diana Waggoner. En su "Theory of Fantasy" afirmó que "[a] fantasy world is a secondary reality whose metaphysical premises are different from those of the real world" (1978: 4). Y añadió una característica que Trębicki parece dar por supuesta: "Fantasy places the material in a fictional framework within which it is treated as empirical data, the common stuff of ordinary reality" (4). Por ello, incluso cuando la magia existe en el mundo secundario épico-fantástico, su construcción ficcional es diferente a la que suele encontrarse en las fantasías maravillosas (sobre todo los cuentos de hadas), que es la modalidad que con más facilidad puede quizá confundirse con la fantasía épica. En ambas modalidades, se produce la manifestación de la presencia de realidades sobrenaturales (o anaturales), pero "in fairy-story this presence is taken for granted. In [high] fantasy, this presence must be realistically established" (Waggoner, 1978: 22), entre otras cosas, mediante la mostración de sus móviles y la lógica de la manifestación anatural dentro de su propio mundo, para que se produzca una inmersión de los lectores (o de los espectadores en el teatro) que les haga creer en la existencia ficcional del mundo secundario, de forma hasta cierto punto semejante a la inmersión perseguida por la ficción mimética. Según Maria Nikolayeva, que se inspira seguramente

sobrenaturales, o con una mezcla de fuerzas naturales y sobrenaturales que no se ocultan y personas ficcionales con una dote alética [sic] normal y/o sobrenatural" (Ariza Trinidad, 2021: 384). 
en Tolkien, "genuine and skilful fantasy creates Secondary Belief (unlike the Primary Belief of myth or religion), putting the reader in a temporary state of enchantment. As soon as suspension of disbelief is disturbed, the spell is broken" (2002: 153), mientras que "the addressee of a fairy tale knows that the story is not true" (153). Además, la intrusión de elementos del mundo fenoménico también perturba en el cuento de hadas la suspensión de la incredulidad o la creencia secundaria. En cambio, las ficciones épicofantásticas "take place in a closed, self-contained Secondary World without any connection with reality. However, unlike fairy tales, they are definitely based on Secondary Belief' (154). Otra característica de la fantasía épica que la separan de la ficción maravillosa es que sus personajes, incluso si no son humanos, tienen una personalidad, y no son "occupational labels" (Waggoner, 1978: 23). Tampoco es convencional en la fantasía épica el medio en el que los personajes se mueven dentro de la ficción, mientras que el mundo del cuento de hadas "is a space where things happen, not a place of itself” (Hunt, 2003: 12). En suma, según la caracterización de la literatura maravillosa de tradición oral hecha por Max Lüthi, y que es aplicable, con todos los matices necesarios que impone cada personalidad autoral, a Kunstmärchen o cuentos artísticos como "El pájaro verde" (Cuentos y diálogos, 1882), de Juan Valera, "[s]eine Gestalten sind Figuren ohne Körperlichkeit, ohne Innenwelt, ohne Umwelt; ihnen fehlt die Beziehung zur Vorwelt und zur Nachwelt, zur Zeit überhaupt” (1976: 13).

Por su parte, la fantasía épica obedece a unos criterios de verosimilitud ficcional que no son operativos en el cuento maravilloso. Es en la verosimilitud de los personajes y de su medio en lo que se funda la creencia en la realidad de los mundos secundarios épicofantásticos durante la inmersión lúdica y artística en ellos que se produce durante su lectura y recepción, gracias a veces a "explanations that are plausible in those other-world settings" (Zahorski y Boyer, 1982: 56). Según Tolkien, un subcreador acierta al concitar la creencia de los lectores en la realidad de ese mundo al acceder mentalmente a él. De hecho, "[h]e makes a Secondary World which your mind can enter. Inside it, what he relates is 'true': it accords with the laws of that world. You therefore believe it, while you are, as it were, inside" (Tolkien, 2014: 52).

Sin embargo, no debemos olvidar que, si bien la verosimilitud de la fantasía épica se alcanza siguiendo procedimientos parecidos a los de la ficción mimética, las "metaphysical premises" (Waggoner, 1978: 4) del mundo secundario épico-fantástico son distintas a las del mundo primario o fenoménico, ya que se trata de un universo esencialmente exomimético. Como tal, no basta con que la ficción se desarrolle en un espacio cuyo nombre indique que no se trata de una realidad presente o pasada de la Tierra. Si así fuera, cabría clasificar como fantasía épica desde las novelas miméticas ambientadas en ciudades provincianas inventadas como la Orbajosa de Doña Perfecta (1876), de Benito Pérez Galdós, hasta las ficciones ruritánicas que se desarrollan en reinos imaginarios en el contexto de la Belle Époque europea, tales como Dacia en El saludo de las brujas (1898), de Emilia Pardo Bazán, pasando por los territorios de utopías (o distopías) coloniales como La conquista del reino de Maya por el último conquistador 
español Pío Cid (1897), de Ángel Ganivet, y los países hispanoamericanos imaginarios de novelas de dictador como Tirano Banderas (1926), de Ramón María del Valle-Inclán. En las ficciones de esta clase no hay más que un mundo primario disfrazado, ya que falta el orden cultural y ontológico autónomo de un mundo secundario que constituye una de las principales características que definen a la fantasía épica y la distinguen de otros tipos de ficción que, al igual que la fantasía maravillosa, admiten la magia o fenómenos imaginarios similares (por ejemplo, intervenciones divinas) y, en consecuencia, un funcionamiento del mundo ficticio imposible en el universo fenoménico. Esto último se produce, por ejemplo, en las fantasías históricas (a menudo arqueológicas) en las que una ambientación en una geografía y época concretas y documentadas por la historia, incluso legendaria, es compatible con la intervención de poderes sobrenaturales, como los de las brujas que celebran aquelarres en la Euskaria (Vasconia) en lucha contra el invasor romano en "La leyenda de Lelo" (Los últimos iberos, 1882), de Vicente de Arana. También es común esa intervención en las fantasías caballerescas europeas de raigambre medieval, con sus encantadores de ambos sexos, dragones, filtros de amor y otros elementos sobrenaturales, como ocurre en el relato artúrico "Edirn y la hamadríada" (Del antaño quimérico, 1905), de Luis Valera, y lo es también en las fantasías exóticas inspiradas en la materia fabulosa árabe (por ejemplo, el cuento "Las razones del nómada", de Armando Boix, publicado primero en 1999) o en otros acervos y escenarios de culturas no europeas, como la leyenda hindú "El caudillo de las manos rojas" (1858), de Gustavo Adolfo Bécquer, aunque existen ficciones propiamente épico-fantásticas ambientadas en mundos secundarios de aspecto oriental, entre las que destaca, al menos por su temprana cronología, el cuento "La esclava perfecta" (1872; recogido en Flores de invierno, 1877), de Federico de Castro.

Aunque tanto las fantasías caballerescas como las que responden a actitudes orientalistas se consideran a menudo épicas, el hecho de que su cosmovisión esté tan inspirada en religiones vivas como la de las fantasías teológicas protagonizadas por mundos y entes divinos de tendencia alegórica (por ejemplo, Andrógino, epopeya en prosa de José Antich publicada en 1904) o la de las fantasías póstumas ambientadas en los mundos de ultratumba del acervo religioso (por ejemplo, "El pórtico de la gloria", cuento de Benito Pérez Galdós publicado en 1896) liga todas estas fantasías de manera esencial a una cultura que aún es la nuestra y, por lo tanto, su mundo ficcional no guarda total autonomía con respecto al mundo primario. Además, aunque dejaran de existir creyentes en las religiones hoy vivas, monoteístas o no, persistiría el vínculo con una realidad histórica específica, vínculo que también mantienen aquellas en que los entes sobrenaturales proceden de mitologías antiguas. Aunque estas no sostengan ya prácticas y ritos religiosos vivos, lo hicieron en el pasado, de manera que el mundo ficcional en que aparezcan no será una creación integral y autónoma de nueva planta. Por ello, las fantasías mitológicas son claramente fantasías, pero no son fantasías épicas si su panteón o personajes proceden, incluso si es con suma libertad, de acervos mitológicos existentes, en Europa sobre todo el griego, como en Menesteos, marinero de abril (1965), de María 
Teresa León, y el hebreo, aprovechado por José Jiménez Lozano en Sara de Ur (1989), sin olvidar las reescrituras de mitos como si hubieran sido intervenciones alienígenas en el pasado en fantasías paleoastronáuticas como el poema épico Utnoa (2018), de Abel Montagut. Algo análogo se puede afirmar de las numerosas fantasías atlantológicas, con elementos sobrenaturales o no, como "La diosa velada" (Del antaño quimérico, 1905), de Luis Valera. En estas últimas, la Atlántida no es un mundo secundario plenamente inventado, ya que procede en última instancia de la correspondiente leyenda platónica, por lo que no cabe su inclusión en la fantasía épica propiamente dicha. Lo mismo puede decirse de las obras que fingen recoger o elaborar un acervo épico legendario previo oral, incluso cuando la transmisión popular es dudosa, como es el caso de muchas leyendas fabulosas ligadas a lugares geográficos concretos en épocas paganas, por ejemplo, "La mujer muerta" (Cuentecillos al aire, 1898), de José Zahonero. Algunas de estas fantasías folclóricas y, a menudo, seudofolclóricas (fakelore en vez de folklore), tuvieron un enorme éxito e incluso hubo una serie temprana que pudo influir en la constitución de la fantasía épica en la medida en que abrió la materia épica a sitios y tiempos antes ignotos a la tradición clásica predominante en Europa hasta finales del siglo XVIII. Se trata de las historias atribuidas al bardo Ossian e imitadas en toda Europa, por ejemplo, por José de Espronceda en "Óscar y Malvina" (1837; Poesías, 1840). En cambio, en la medida que los textos editados o traducidos (himnos, fragmentos históricos o míticos, etc.) emanen de religiones y civilizaciones antiguas inventadas, al menos esos supuestos testimonios podrían considerarse ficciones épico-fantásticas en el seno de fantasías filológicas tales como "Extractos, documentación y fuentes relativos al culto de Yidhra y su relación con el ciclo mítico de Mlandoth" (1979), de Emilio Serra, si bien la adopción de una perspectiva filológica contemporánea en el marco que encuadra y comenta los textos traducidos matiza su autonomía semiótica y, en consecuencia, la independencia y clausura del mundo secundario generado por esos supuestos documentos antiguos.

Casos como este de dudosa definición nos recuerdan que, si bien los principios determinantes de la clasificación están claros en términos generales desde el punto de vista de la semántica del mundo ficcional e incluso lingüística, como pronto veremos al hilo de la onomástica épico-fantástica, la definición de especies literarias no es una ciencia exacta, como tampoco lo es su objeto. Se pueden aducir a este respecto obras en las que los elementos del mundo primario (por ejemplo, una mitología o religión históricas) son marginales en un universo ficticio que presenta todas las características de los mundos épico-fantásticos, de manera que su clasificación dentro o fuera de este tipo de ficción responde a una decisión hermenéutica, según se haga hincapié en un aspecto u otro. Un ejemplo insigne de ello es Olvidado rey Gudú (1996). En esta novela de Ana María Matute conviven cristianos y adeptos de religiones paganas inventadas, según el pueblo al que pertenecen los personajes. Esto convierte a esta novela en un ejemplo de ficción híbrida que podría clasificarse en la fantasía maravillosa si consideramos la semejanza voluntaria del funcionamiento del mundo de Gudú con el de los cuentos de hadas y, tal vez en mayor medida, con el de las fantasías elficológicas protagonizadas por 
espíritus elementales (ondinas, gnomos, etc.), tales como los que constituyen un mundo paralelo al fenoménico, pero ya cristianizado, en la breve novela "La ahijada de los silfos" (Del antaño quimérico, 1905), de Luis Valera. Por otra parte, Olvidado rey Gudú puede considerarse una obra épico-fantástica si observamos que el cristianismo es un elemento completamente accesorio en ella y que su mundo tiene un funcionamiento autónomo y, además, es cerrado, tal y como subraya la desaparición final del imaginario reino de Olar. Además, a diferencia de los nombres de las novelas caballerescas de William Morris tradicional y erróneamente consideradas pioneras de la fantasía épica, la onomástica de Olvidado rey Gudú es inventada. Esta característica se puede considerar una marca lingüística fácilmente reconocible de la escritura épico-fantástica:

For the fantasy to induce the necessary suspension of disbelief, the secondary world must be remote in space, time, and/or dimension from the primary or real world. The nomenclature is one important way in which this remoteness is achieved and sustained (Burelbach, 1982: 135).

Según Lin Carter, "[i]n creating an imaginary world with words, the author is thrust into the role of Adam. Everything must be named" (1973: 192-193). La onomástica y toponimia imaginarias (o correspondientes a realidades históricas diversas y ajenas al mundo ficticio creado) indican claramente que el universo ficcional puede estar inspirado en mitos o sucesos existentes en el mundo fenoménico, pero que no se refieren a este. La creación de nombres es una sinécdoque de la creación del mundo ficcional autónomo en la fantasía épica.

Esta clase de mundo secundario presenta otras características convencionales distintivas. La fantasía épica surgió modernamente como el resultado de una especulación arqueohistórica y mitológica inspirada en los avances de las ciencias humanas. La dimensión especulativa de la fantasía épica se suele construir por analogía con los mitos, creencias, costumbres y ordenamiento de las sociedades antiguas y exóticas, antes desconocidas o no estudiadas científicamente, que la Arqueología, la Mitografía, la Filología y la Etnografía modernas han ido revelando al público interesado desde al menos los inicios del siglo XIX. En consecuencia, aunque la fantasía épica pueda tener precedentes en la Historia de la Literatura, se trata de una clase de ficción que surge en el contexto occidental moderno, habiendo emergido "from the awareness of a distance between the modern world and the mythological past" (Moran, 2010: 15). Según Corin Braga, "la littérature fantasy actuelle [...] est une pseudo-morphose, modelée par l'esprit positiviste et réaliste, par la sensibilité et le goût contemporain, de la littérature magique et féerique traditionnelle" (2018: 44). Esto puede explicar la apariencia maravillosa, mítica o legendaria de la fantasía épica, que deriva de su frecuente ambientación en un período del pasado muy alejado en el tiempo (a veces, también en el espacio en el caso de las historias ambientadas fuera de la Tierra). Se trata, además, de unos mundos que, a diferencia del fenoménico, admiten a menudo, como señalamos arriba, la acción de fuerzas sobrenaturales y la intervención de figuras no humanas, generalmente de carácter 
inventado y anatural, esto es, no se trata de personajes de minerales, vegetales o animales antropomorfizados, que son las criaturas que protagonizan las fantasías fabulísticas, incluidas aquellas cuyos mundos ficticios son autónomos, como el de las hormigas de "Formio XXVI" (1890; Artículos de fantasía, 1894), de Sinesio Delgado. Por eso, al faltar en ella las realidades históricas y naturales del mundo primario que sirven de referencia a las fantasías históricas, mitológicas, teológicas o fabulísticas, la fantasía épica puede resultar difícil de comprender y aceptar para unos lectores y espectadores acostumbrados a las convenciones de la ficción mimética triunfante en la Modernidad. Por otra parte, el sumo alejamiento de sus mundos secundarios en el tiempo y el espacio puede facilitar la creencia en la verosimilitud realista de los elementos de la fantasía épica contrarios a las leyes naturales de nuestro universo, pues tales elementos se suelen considerar propios de la cosmovisión de las sociedades premodernas.

Desde este punto de vista, la presencia de tecnología posterior a la Revolución Industrial supondría una contaminación heterocrónica de la realidad contemporánea que parece ser ajena a la fantasía épica propiamente dicha, tal como se ha ido constituyendo desde el siglo XIX como ficción de mundos secundarios temporal y espacialmente exóticos. Esto es así incluso cuando tal contaminación se produce en el seno de mundos secundarios dotados de amplia autonomía y sin una adscripción religiosa determinada, ni una localización geográfica o cronológica concretas, como serían los países imaginarios que sirven de parábolas de distintos ordenamientos sociopolíticos en fantasías políticas como el drama Anastas o el origen de la Constitución (1971), de Juan Benet. En cambio, la ausencia de tecnología postindustrial y la presencia de elementos fabulosos en un futuro normalmente muy lejano que funciona con leyes distintas a las de nuestro universo facilitan construir mundos secundarios plena y metafísicamente distintos al fenoménico, a la manera de la fantasía épica. Es el caso de la modalidad ficcional que en la angloesfera se suele denominar dying earth fiction y que podríamos llamar en castellano fantasía prospectiva. En ella se puede clasificar una novela como Temblor (1990), de Rosa Montero, cuya heroína se enfrenta a un opresivo matriarcado distópico y está dotada de poderes mágicos, por ejemplo, la "mirada preservativa" que opone al avance de la entrópica niebla que está haciendo desaparecer su mundo. Dada la inventada peculiaridad del orden cultural y metafísico que subyace a tal mundo, la mera ambientación en el futuro no justifica considerar que esta y otras fantasías prospectivas formen parte de la ciencia ficción o ficción científica, cuyas manifestaciones suelen ambientarse en un futuro tecnológicamente avanzado, tal y como ocurre, por ejemplo, en La bomba increíble (1950), de Pedro Salinas. Al ser los mundos secundarios de la fantasía prospectiva autónomos y cerrados, además de no tecnológicos, podrían caber mejor dentro de la fantasía épica.

Esta clasificación parece más dudosa cuando el mundo ficcional de aire épicofantástico sí es autónomo, pero no cerrado, tal y como ocurre cuando se produce una intrusión del mundo primario en el secundario. La ficción se inicia ahí en forma mimética en el mundo primario representado, que puede coincidir con la realidad fenoménica o con 
un universo sobrenatural si este corresponde a una entidad aceptada como real por la tradición religiosa o mítica como, por ejemplo, la ultratumba desde la que Dante viaja a "La Ciudad Eterna" (1902) en el cuento así titulado de Francisco Navarro Ledesma. Luego se produce el acceso desde el mundo primario al mundo secundario por medios no miméticos, a diferencia de los viajes imaginarios ${ }^{9}$ de la (proto)ciencia ficción (por ejemplo, El archipiélago maravilloso [1923], de Luis Araquistáin), de las arqueoficciones o ficciones sobre mundos perdidos (por ejemplo, Mundo macho [1998], de Terenci Moix) y de los planetary romances o fantasías planetarias, por ejemplo, "Sagrada" (Sagrada, 1989), de Elia Barceló. La llegada al mundo secundario en la fantasía épica se produce atravesando algún límite o confín cuyo efecto no tiene explicación desde el punto de vista del funcionamiento normal del mundo fenoménico. Ese límite que se franquea puede ser virtual (un ensueño, una transferencia psíquica, etc.) o material, como el armario que sirve de comunicación entre nuestro mundo arrasado por la Segunda Guerra Mundial y el fabuloso de Narnia en la correspondiente serie de novelas de C. S. Lewis. Este armario funciona, pues, como un umbral o un portal, tal como indica el nombre inglés de portal fantasy empleado en esta clase de ficciones, que podría traducirse por fantasía liminar. Salvo si se puede entender que el personaje o personajes que acceden a un territorio determinado del mundo secundario proceden también de este último, aquel umbral que conlleva el marco narrativo entraña la existencia de un vínculo directo con el mundo primario que anula la completa autonomía del secundario. En fantasías liminares como las que constituyen el ciclo de Harry Potter de J. K. Rowling o la trilogía de Memorias de Idhún (2004-2006), de Laura Gallego, la experiencia ficcional no es inmersiva como lo es en la fantasía épica propiamente dicha, en la que el lector se ve confrontado desde el principio y sin mediadores ni mediaciones con un mundo desconocido, cuyas leyes ha de entender a partir de los indicios ofrecidos por la propia ficción. Esto supone una dificultad para numerosos lectores reacios a aceptar el pacto de lectura de la literatura exomimética. Además, la ausencia de precisos referentes históricos, mitológicos o de otro tipo existentes en el mundo primario a los que recurrir para comprender el funcionamiento de los mundos secundarios de la fantasía épica puede explicar, por una parte, que los autores hayan deseado a menudo facilitar la recepción por medio de un marco mimético ambientado en el mundo primario y, por otra, que la fantasía épica haya sido, a diferencia de la ficción científica, una literatura de limitado desarrollo en sus inicios incluso allí donde nació, en Europa y sus dependencias lingüísticas de ultramar.

Con todo, pueden recordarse varias obras tempranas sumamente interesantes ya desde sus primeras manifestaciones, tales como el apólogo "The Sons of Iron" [Los hijos del hierro], intercalado en la novela de 1833 Arthur Coningsby, de John Sterling. Muchas de esas obras son hoy casi desconocidas, pero su redescubrimiento demostraría que la

\footnotetext{
${ }^{9}$ Tolkien excluye de la fantasy los viajes imaginarios, porque "[s]uch tales report many marvels, but they are marvels to be seen in this mortal world in some region of our own time and space; distance alone conceals them" (2014: 34).
} 
fantasía épica existía como tal mucho antes del éxito mundial de The Lord of the Rings [El señor de los anillos] (1954-1955), de Tolkien, y que su desarrollo fue mucho más internacional de lo que nos haría creer el actual predominio aplastante de la fantasía épica en inglés y la perspectiva estrechamente nacional(ista) que suelen aplicar los estudiosos de la angloesfera ${ }^{10}$. Hubo diversos experimentos anteriores en otras regiones lingüísticas, sobre todo en la francesa, y tampoco faltan obras fundamentales de la fantasía épica temprana incluso en literaturas menos conocidas como la letona, sobre todo la tragedia de la poetisa Aspajiza Sidraba šķidrauts [El velo de plata], estrenada triunfalmente en 1905. Grandes clásicos modernos también la cultivaron tempranamente, desde George Sand, cuya novela Évenor et Leucippe [Evenor y Leucipa] (1856) es tal vez la primera novela épico-fantástica moderna (Martín Rodríguez, 2020), hasta Gabriele D’Annunzio, cuyo breve poema narrativo titulado en su versión definitiva "Il sangue delle vergini" [ $\mathrm{La}$ sangre de las vírgenes] (1894) no tiene rival en su género textual ${ }^{11}$, salvo quizás "L'honor real" [El honor real] (1887), de Àngel Guimerà. La trama de estas tres obras se desarrolla en mundos secundarios inventados, llamados Éden por Sand, Cheresto por D'Annunzio e Hiriot por Guimerà. Lo mismo ocurre con la primera gran narración épico-fantástica en castellano, la breve novela "Dyusandir y Ganitriya" (Visto y soñado, 1903), de Luis Valera, que se desarrolla en un imaginario imperio puruna.

Así pues, la fantasía épica era en sus orígenes un tipo de ficción cultivado ocasionalmente en muy diversos países de cultura europea, desde Portugal ("A voluptuosidade e o amor" [La voluptuosidad y el amor], cuento de Raul Brandão publicado en 1896) hasta los Países Bajos (Fidessa [Fidessa], novela breve de 1899 de Louis Couperus), y desde Brasil (una rara distopía épico-fantástica de 1895 titulada

${ }^{10}$ Como muestra de ello, en la mejor historia de la fantasía épica temprana en lengua inglesa, su autor declara que "while work bearing a clear relation to British/Irish/Anglo-American fantasy (with regard to both form and influence) appears in the continental European literatures, the kind of tradition that ultimately culminates in the establishment of a separate phenomena, a separable genre, does not" (Williamson, 2019: 43). Lo irónico del asunto es que el estudioso demuestra en su libro precisamente que, hasta bien entrada la década de 1960, las no muy numerosas obras que podrían considerarse en puridad épicofantásticas constituyeron experimentos aislados en inglés, exactamente igual que en otras lenguas europeas. No hay diferencia alguna esencial entre unas literaturas y otras antes del éxito de Tolkien y la cristalización de la fantasy a raíz de las colecciones editadas por Lin Carter.

${ }^{11}$ Aunque la fantasía épica se manifiesta actualmente sobre todo en el género de la novela, sus discursos han sido históricamente muy variados, no limitándose ni mucho menos al novelístico. Para la creación literaria de mundos ficcionales épico-fantásticos se ha recurrido también a otros tipos textuales del acervo genérico constituido a lo largo de la historia. Entre ellas se cuentan el drama (por ejemplo, "El templo sin Dios", publicado en 1918 en Lunes antes del alba, obra de Ramón María Tenreiro), el poema narrativo o descriptivo en verso (por ejemplo, "Las xanas", recogido por Salvador Rueda en su libro de 1893 En tropel) e incluso géneros discursivos derivados de la escritura de las ciencias humanas, sobre todo de aquellas más propicias a la presentación de materia épica, tales como la historiografía (por ejemplo, "Los príncipes concordes", texto rescatado por Rafael Sánchez Ferlosio en 2005 en El geco de su amplio material sobre las imaginarias Guerras Barcialeas) y la mitografía (por ejemplo, los "Cuentos y leyendas" y otros textos mitográficos de la muy completa Enciclopedia de Idhún, cuya publicación en 2014 aportó una enorme variedad de información documental a ese universo ficcional de Laura Gallego), sin olvidar la etnografía, sobre todo para la descripción del funcionamiento consuetudinario de sociedades inventadas no modernas (por ejemplo, "La filosofía política mandarinesca", trabajo universitario de Miguel Espinosa dado a conocer en 1956). 
"Hiranyo e Garbha" [Hiranyo y Garbha], de Nestor Vítor) hasta Rusia (“"Звезда" [La estrella], relato de 1903 de Vikenty Vikentyevich Veresáyev [Викентий Викентьевич Bepecaeв]). Esta diversidad de la fantasía épica en sus inicios no impide reconocer que la figura más influyente en su constitución como modalidad literaria independiente fue el angloirlandés Lord Dunsany, cuyo papel a este respecto puede considerarse equivalente al de H. G. Wells en la ficción científica, hasta el punto de haber eclipsado al primer gran autor anglófono de fantasía épica para lectores adultos, Laurence Housman, autor de la muy original e irónica novela breve "Gods and Their Makers" [Los dioses y sus hacedores] (1897). Por otra parte, tampoco se debe olvidar que tanto Lord Dunsany como otros pioneros de este tipo de ficción en lengua inglesa (Kenneth Morris, H. P. Lovecraft, Clark Ashton Smith, etc.) desarrollaron su característico estilo preciosista de la purple prose [prosa morada] siguiendo el modelo de la écriture artiste [escritura artística] francobelga, que es la empleada en valiosos relatos épico-fantásticos simbolistas, por ejemplo, de Éphraïm Mikhaël ("L'évocateur" [El evocador], 1890), Bernard Lazare ("La vie sans effroi" [La vida sin temor], 1891), Marcel Schwob ("Le roi au masque d'or" [El rey de la máscara de oro], 1893), Jehan Maillart ("Le Triomphateur" [El Triunfador], 1895), Édouard Ducoté ("La ville aux aveugles" [La ciudad de los ciegos], 1897), Remy de Gourmont ("La ville des shynx" [La ciudad de las esfinges], 1898), Gabriel de Lautrec ("Le mur" [El muro], 1898), Victor-Émile Michelet ("Holwennioul" [Holwennioul], 1899) y Camille Mauclair (Le Poison des pierreries [El veneno de las piedras preciosas], 1903), así como en narraciones ambientadas en una prehistoria épico-fantástica de J.-H. Rosny Aîné ("Les Xipéhuz” [Los Xipehuz], 1887) y André Lichtenberger (Les Centaures [Los centauros], 1904). Todas estas obras se publicaron antes de que Lord Dunsany diera a conocer en 1905 su primer mundo secundario épico-fantástico en la colección de mitos inventados The Gods of Pegāna [Los dioses de Pegana], de manera que puede afirmarse que la fantasía épica no fue una invención inglesa, sino que surgió de forma paralela en diversas literaturas europeas y americanas.

Entre 1905 y 1955 se mantuvo también el cultivo autónomo de la fantasía épica literaria fuera de la angloesfera, a juzgar por poemas como "Le château des masques" [ $E l$ castillo de las máscaras] (1918), de Maurice Magre; novelas como Die Frau ohne Schatten [La mujer sin sombra] (1919), de Hugo von Hofmannsthal; mitos como los de la serie de Fables des origines [Fábulas de los orígenes] (1923), de Henri Michaux; dramas como Răzbunarea pământului [La venganza de la tierra] (1938), de Nicolae Iorga, y cuentos como "Las ruinas circulares" (1940), de Jorge Luis Borges. Incluso tras su cristalización definitiva a raíz del triunfo de The Lord of the Rings, siguieron publicándose obras destacadas de este tipo de ficción en lenguas distintas a la inglesa, tales como Legendele Țării lui Vam [Leyendas del País de Vam] (1961), de Vladimir Colin; Ptah-Hotep [Ptah-Hotep] (1971), de Charles Duits; Ronja Rövardotter [Ronja, la hija del bandolero] (1981), de Astrid Lindgren; "Do Deus memória e notícia" [Del Dios memoria y noticia] (1981), de Mário de Carvalho; Stein und Flöte [Piedra y flauta] (1983), de Hans Bemmann; Kalpa imperial (1983-1984), de Angélica Gorodischer; 
L'últim guerrer [El último héroe] (1986/1995), de Vicent Pascual, y "La torre" [La torre] (1990), de Giorgio Prodi, a las que podrían añadirse los populares títulos de la saga de Geralt z Rivii (Geralt de Rivia) publicados entre 1993 y 2013 por Andrzej Sapkowski.

Este esbozo histórico presenta seguramente graves lagunas, que habrían de subsanarse en una historia bien documentada de la fantasía épica, pero esta tarea está por hacer tanto en el mundo hispánico como en otras regiones culturales ${ }^{12}$. Antes de acometerla, parece claro que convendría precisar de qué se habla exactamente cuando se habla de fantasía épica o high fantasy. A este respecto, si afirmamos que los orígenes internacionales de la fantasía épica son los arriba resumidos, es porque creemos que todas las obras así clasificadas presentan características esenciales coincidentes. En todas ellas se persigue un efecto de inmersión completa en sus mundos secundarios en el tiempo de la lectura. Esta inmersión no se produce en cualquier clase de mundo secundario, sino en aquellos que los autores construyen atendiendo a las exigencias de una verosimilitud acorde con los procedimientos y afirmaciones de las ciencias humanas, y principalmente de la Historiografía, la Mitografía, la Etnografía y la Filología. El mundo secundario resultante tiene un carácter legendario y exótico y en él se admite a menudo la existencia de entes y sucesos sobrenaturales derivados de una cosmovisión antigua, propia de las civilizaciones paganas del pasado. Esta ambientación no basta, sin embargo, para definir la fantasía épica, pues existen numerosas ficciones históricas y arqueológicas ambientadas en civilizaciones de aquel tipo. Lo que define estructuralmente a los mundos secundarios de la fantasía épica es otra cosa:

The basic structure of SWF [secondary world fantasy] is [...] placing the plot in a world whose technological level is rather low and spatial parameters closed, and which is presented as a reality not connected with the mimetic universe either spatially or temporally (Trębicki, 2011: 45).

En otras palabras, los universos ficticios de la fantasía épica, que son completos ${ }^{13} \mathrm{y}$ cerrados, tienen sus propios parámetros espaciales y temporales, su propio orden social, cultural y ontológico, y su propia causalidad, que puede ajustarse o no a las leyes naturales de nuestro mundo fenoménico, pero que es coherente ${ }^{14}$ y lógica dentro de sus universos especulativos. Tales universos se construyen de manera realista, procurando que

\footnotetext{
${ }^{12}$ Hay varias historias interesantes y útiles de carácter divulgativo y ámbito general, como la escrita por Silvia Pato (2019), o limitadas a una literatura nacional, como la italiana de Franco Ressa (2012), pero todas ellas presentan las inevitables carencias derivadas de una insuficiente caracterización de la fantasía épica como modalidad ficcional específica y de la escasez de trabajos previos de documentación literaria del pasado de la fantasía épica como tal, fuera de la angloesfera.

${ }^{13}$ Los mundos imaginarios son naturalmente incompletos, pero aquí su completitud "refers to the degree the world contains explanations and details covering all the various aspects of its character's experience, as well as background details which together suggest a feasible, practical world" (Wolf, 2012: 38). Este procedimiento "causes the audience to automatically fill in the missing pieces of that world, based on the details that are given" (52), de manera que incluso textos muy breves y altamente simbólicos pueden dar esa impresión de completitud, al menos potencial.

${ }^{14}$ Coherentes en el sentido de que los "world details are plausible, feasible, and without contradiction" (Wolf, 2012: 43).
} 
parezcan verosímiles de acuerdo con sus propias premisas lingüísticas, étnicas, históricas y míticas imaginarias. Además, los mundos secundarios de la fantasía épica suelen presentar una onomástica y toponimia inventadas, lo que constituye un indicio lingüístico fácil de reconocer para distinguir un universo épico-fantástico de cualquier otro de los universos fabulosos propios de otros tipos de ficción que se suelen clasificar erróneamente dentro de la fantasía épica, la modalidad literaria cuyas características específicas hemos intentado esbozar en estas páginas.

\section{REFERENCIAS BIBLIOGRÁFICAS}

ARIZA TRINIDAD, E. (2021). "Mundos posibles de lo fantástico. Una aproximación a la estructura de mundo". Signa 30, 363-390. Disponible en línea: https://doi.org/10.5944/signa.vol30.2021.26399 [19/03/2021].

Braga, C. (2018). Pour une morphologie du genre utopique. Paris: Classiques Garnier. BurelbaCH, F. M. (1982). "An Introduction to Naming in the Literature of Fantasy". Literary Onomastic Studies 9, 131-148. Disponible en línea: https://digitalcommons.brockport.edu/los/vol9/iss1/11/[19/03/2021].

Clute, J., ED. (1998). The Encyclopedia of Fantasy. New York: St. Martin's Griffin.

Cornwell, N. (1990). The Literary Fantastic: From Gothic to Postmodernism. Hertfordshire: Wheatsheaf.

ESPEZÚA SALMÓN, D. (2006). "Ficcionalidad, mundos posibles y campos de referencia". Dialogía: Revista de Lingüistica, Literatura y Cultura 1, 69-96. Disponible en línea: https://journals.uio.no/Dialogia/article/view/4041 [19/03/2021].

Hunt, P. (2003). "Fantasy and Alternative Worlds". En Alternative Worlds in Fantasy Fiction, P. Hunt \& M. Lenz (eds.), 1-41. London / New York: Continuum.

IRwIN, W. R. (1976). The Game of the Impossible: A Rhetoric of Fantasy. Urbana / Chicago / London: University of Illinois Press.

LÓPEZ-PellisA, T., ED. (2018). Historia de la ciencia ficción en la cultura española. Madrid / Frankfurt am Main: Iberoamericana / Vervuert.

LÜTHI, M. (1976). Das europäische Volksmärchen. München: Francke.

MARTín Rodríguez, M. (2020). "The Modern High Fantasy Novel was Born in France: An Essay on Reverse Literary History". SFRA Review 50.4, 13-24. Disponible en línea: https://sfrareview.org/2020/12/13/50-4-4/ [19/03/2021].

Mendlesohn, F. (2008). Rhetorics of Fantasy. Middletown: Wesleyan University Press. Moran, P. (2019). The Canons of Fantasy Lands of High Adventure. Cambridge: Cambridge University Press.

Nikolayeva, M. (2002). "Fantasy Literature and Fairy Tales". En The Oxford Companion to Fairy Tales: The Western Fairy Tale Tradition from Medieval to Modern, Jack Zipes (ed.), 150-154. Oxford: Oxford University Press.

PAto, S. (2019). Breve historia de la fantasía. Madrid: Nowtilus. 
Pesch, H. W. (1990). Fantasy: Theorie und Geschichte einer literarischen Gattung. Passau: Erster Deutsche Fantasy Club.

RESSA, F. (2012). Il fantasy in Italia. Chieti: Solfanelli.

ROAS, D., ED. (2017). Historia de lo fantástico en la cultura española contemporánea (1900-2015). Madrid / Frankfurt am Main: Iberoamericana / Vervuert.

RoBles, L. (2018). En regiones extrañas: Un mapa de la ciencia ficción, lo fantástico y lo maravilloso. Madrid: Cazador.

Rodríguez PEQUeÑo, J. (2008). Géneros literarios y mundos posibles. Madrid: Eneida. Todorov, T. (1976). Introduction à la littérature fantastique. Paris: Seuil.

Tolkien, J. R. R. (2014), Tolkien on Fairy Stories, V. Flieger \& D. A. Anderson (eds.). London: HarperCollinsPublishers.

TręBICKI, G. (2011). "Mythic Elements in Secondary World Fantasy and Exomimetic Literature”. En Mityczne scenariusze. Od mitu do fikcji, od fikcji do mit, T. Ratajczak \& B. Trocha (eds.), 41-52. Zielona Góra: Oficyna Wydawnicza Uniwersytetu Zielonogórskiego.

(2014). "Supragenological Types of Fiction versus Contemporary Non-Mimetic

Literature". Science Fiction Studies 41.3, 481-501.

Waggoner, D. (1978). The Hills of Faraway: A Guide to Fantasy. New York: Atheneum.

Williamson, J. (2019). The Evolution of Modern Fantasy: From Antiquarianism to the Ballantine Adult Fantasy Series. Hampshire: Palgrave Macmillan.

Wolf, J. P. M. (2012). Building Imaginary Worlds: The Theory and History of Subcreation. New York / London: Routldege.

ZAHORSKI, K. J. \& BOYER, R. H. (1982). “The Secondary Worlds of High Fantasy”. En The Aesthetics of Fantasy Literature and Art, R. C. Schlobin (ed.), 56-81. Notre Dame / Brighton: University of Notre Dame Press / The Harvester Press.

ZGORZELSKI, A. (1984). “On Differentiating Fantastic Fiction: Some Supragenological Distinctions in Literature". Poetics Today 5.2, 299-307.

ZIPFEL, F. (2001). Fiktion, Fiktivität, Fiktionalität: Analysen zur Fiktion in der Literatur und zum Fiktionsbegriff in der Literaturwissenschaft. Berlin: Erich Schmidt.

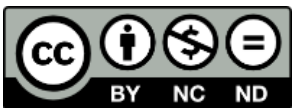

This work is licensed under a Creative Commons AttributionNonCommercial-NoDerivatives 4.0 International (CC BY-NC-ND).

Fecha de recepción: 25/01/2021

Fecha de aceptación: 30/04/2021 